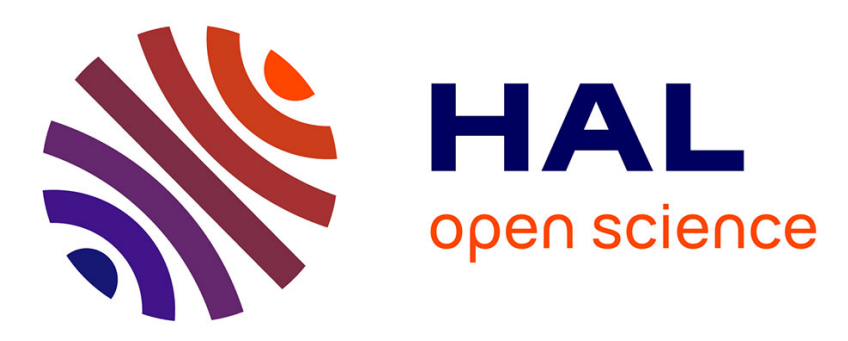

\title{
Reliability assessment and updating of notched timber components subjected to environmental and mechanical loading
}

T.-B. Tran, Emilio Bastidas-Arteaga, Y. Aoues, C F Pambou Nziengui, S E Hamdi, R Moutou Pitti, E. Fournely, Franck Schoefs, A. Chateauneuf

\section{To cite this version:}

T.-B. Tran, Emilio Bastidas-Arteaga, Y. Aoues, C F Pambou Nziengui, S E Hamdi, et al.. Reliability assessment and updating of notched timber components subjected to environmental and mechanical loading. Engineering Structures, 2018, 166, pp.107-116. 10.1016/j.engstruct.2018.03.053 . hal-01756794

\section{HAL Id: hal-01756794 \\ https://hal.science/hal-01756794}

Submitted on 2 Jul 2018

HAL is a multi-disciplinary open access archive for the deposit and dissemination of scientific research documents, whether they are published or not. The documents may come from teaching and research institutions in France or abroad, or from public or private research centers.
L'archive ouverte pluridisciplinaire HAL, est destinée au dépôt et à la diffusion de documents scientifiques de niveau recherche, publiés ou non, émanant des établissements d'enseignement et de recherche français ou étrangers, des laboratoires publics ou privés. 
Tran T-B, Bastidas-Arteaga E, Aoues Y, Pambou Nziengui CF, Hamdi SE, Moutou Pitti R, Fournely E, Schoefs F, Chateauneuf A. (2018). Reliability assessment and updating of notched timber components subjected to environmental and mechanical loading. Engineering Structures, 166: 107-116 https://doi.org/10.1016/j.engstruct.2018.03.053

\title{
Reliability assessment and updating of notched timber components subjected to environmental and mechanical loading
}

\author{
T-B Tran ${ }^{1}$, E. Bastidas-Arteaga ${ }^{1,}$, Y. Aoues ${ }^{2}$, C.F. Pambou Nziengui ${ }^{3}$, S.E. Hamdi ${ }^{3}$, R. Moutou Pitti ${ }^{3,4}$, \\ E. Fournely ${ }^{3}$, F. Schoefs ${ }^{1}$, A. Chateauneuf ${ }^{3}$ \\ ${ }^{I}$ UBL, Université de Nantes, GeM, Institute for Research in Civil and Mechanical Engineering/Sea and Littoral Research \\ Institute, CNRS UMR 6183/FR 3473, Nantes, France \\ ${ }^{2}$ Laboratoire d'Optimisation et Fiabilité en Mécanique des Structures (LOFIMS), INSA de Rouen, France \\ ${ }^{3}$ Université Clermont Auvergne, CNRS, Institut Pascal, Clermont-Ferrand, France \\ ${ }^{4}$ CENAREST, IRT, Libreville, Gabon
}

\begin{abstract}
Cracking initiation and propagation are frequently recognized as main causes leading to failure of timber structures. Since the kinematics of both processes is largely influenced by environmental conditions, a comprehensive reliability assessment of notched structures should take into account such environmental factors. The main purpose of this paper is to propose a methodology for reliability assessment and updating of notched timber components based on mechanical (A-integral formulation) and reliability (simulation and Bayesian networks) methods, and experimental data. The A-integral formulation is used to estimate energy release rates in modes I and II by taking into account thermal effects; but its numerical implementation is time-consuming for uncertainty propagation. In order to deal with this problem, Bayesian networks were used for reliability assessment and updating. The experimental data used for updating purposes were obtained from measurements of deflection, temperature and relative humidity on a notched beam (Douglas Fir specie) exposed to outdoor environment and constant loading. The whole proposed methodology was illustrated with the reliability assessment and updating of the studied notched beam. The results indicated that the proposed approach is able to integrate measurements of temperature and deflection for reliability updating.
\end{abstract}

Keywords: timber; Bayesian network; reliability; updating; mixed mode fracture; viscoelasticity

\section{Introduction}

Timber is a traditional material that has been widely used for various types of structures. For example, there are about 27,000 timber bridges over a total of 40,000 bridges in Australia [1]. By observing historical buildings around the world, it can be seen that timber structures guarantee a long-term

\footnotetext{
* Corresponding author: Address: 2 rue de la Houssinière BP 99208, 44322 Nantes Cedex 3 France. Phone: +33 2511255

24.Email: emilio.bastidas@univ-nantes.fr
} 
service life with a high durability level. However, in timber structures, cracking initiation and propagation are frequently recognized as main causes leading to structural failure [2,3]. Hansson [4] provided a comprehensive survey and analysis of failures in 127 timber structures in Sweden. This author found that crack initiation and propagation play an important role in timber structural failure. Mechanical behavior of notched timber structures is affected by environmental conditions (moisture, temperature, etc.) $[5,6]$ that could produce a higher risk of crack growth in timber structures $[7,8]$; as a consequence, the lifetime assessment of notched timber structures should take into account the influence of these environmental conditions.

Rational reliability and lifetime assessments require a realistic modeling of the mechanical behavior. Concerning crack growth initiation, many numerical methods have been developed to characterize mechanical fields at the crack tip vicinity $[9,10]$. Among them, the most popular energy methods enable an evaluation of fracture parameters such as energy release rate and stress intensity (J-integral [11] and Noether's Theorem [12]). These methods however are inefficient when solving mixed-mode crack growth problems that require separating the displacement fields into symmetric and asymmetric parts. To deal with this problem, the M-integral [13] separates fracture modes based on a bilinear form of the strain energy density by introducing real and virtual mechanical fields according to Sih's singular forms. Unfortunately, these tools remain mathematically limited to simple loadings and simple boundary conditions. This work, considers an extension of the T-integral formulation called Aintegral to take into account the effect of thermal loading and therefore improve the estimation of the fracture parameters, such as stress intensity factors and energy release rates (see $[2,14,15]$ for more information on the definitions and formulations of $\mathrm{T}$ and A-integrals).

Several authors [16-23] used reliability theory and methods to evaluate the structural safety of new or existing timber structures. Brites et al. [16] used reliability analysis based on Monte Carlo simulations to evaluate the safety of the timber truss system subjected to decay. Köhler et al. [19] focused on the development of comprehensive probabilistic models of timber material properties including spatial variability. More recently, Köhler and Svensson [20] worked on a probabilistic representation of the duration of load effects. Sørensen [21] provided a theoretical framework for robustness assessment of timber structures on the basis of structural system reliability and risk analysis. Kirkegaard et al. [22] studied system reliability of timber structures considering its ductile behavior. The results of such a study showed that considering the ductile behavior of timber materials could increase the reliability of a structural timber system. Other authors $[1,18,24]$ assessed the structural safety of existing timber structures by using reliability analysis and measured data (from inspection results and non-destructive tests) for updating purposes. However, these studies did not account for some aspects that might lead to inaccurate assessments such as the presence of notches and the interaction between environmental conditions and mechanical behavior.

A Bayesian based approach is a suitable tool that could incorporate all these issues for reliability assessment. In the form of multi-events, it turns in the form of Bayesian network (BN) for describing the relationship between random variables. This approach has been used for reliability updating in some previous studies related to chloride-ingress into concrete [25-28]. Within this context, the objective of this study is to propose a methodology for reliability assessment and updating of cracked timber structures from experimental data by coupling mechanical (A-integral formulation) and probabilistic (simulation and $\mathrm{BN}$ ) methods. The proposed framework is modeled by a BN that represents the structural performance, provides an estimation of the failure probability and could be updated by introducing experimental information. With respect to previously mentioned works on reliability assessment [1,18,24] [16-23] [16] [19] [20] [21] [22], Analytical formulations, numerical tools and experimental data presented in this paper were developed within the framework of the JCJC2013 CLIMBOIS (effects of climatic and mechanical variations on the durability of timber structures) research project (funded by the French National Research Agency).

The paper starts describing the experimental setup and the inspection data that will be used for reliability updating (section 2). Section 3 summarizes the A-integral formulation as well as the considerations for its numerical implementation in the finite element software Cast3M. Section 4 
introduces the methods for reliability propagation, assessment and updating. Finally, the proposed methodology is applied to the notched beam and the results are presented and discussed in section 5 .

\section{Experimental setup}

\subsection{General description}

This section summarizes the experimental setup considered in this study. The tests were carried out on notched beams of Douglas fir (Pseudotsuga menziesii) specie, dimensioned as presented in Figure 1 according to the Eurocode 5 [29]. Three beams (D3, D6 and D9) have been loaded during this period but only the beam D9 has been studied in this paper. The beams D3 and D6 were broken 2 and 4 hours respectively after the beginning of the experiment. Since this work focuses on environmental effects of climate and loading conditions on the time response of cracked timber beams and the data for beams D3 and D6 is scarce, we will only focus on the results for the beam D9. The initial crack size, $a_{\text {ini }}$, had a length of $25 \mathrm{~mm}$. The beams were subjected to two constant loads, $P$, induced by concrete blocks applied in two points. Before the experiment, the beams were conserved under controlled room environmental conditions (relative humidity $R H=40 \%$, and temperature $T=22^{\circ} \mathrm{C}$ ). Some defects were observed on the beams: knots and annual rings not oriented in the direction of the grain. They were placed at the Clermont Auvergne University (Clermont-Ferrand, France) and subjected to outdoor climatic conditions (Figure 1).

Before applying the load, comparators and a linear graduated line were placed on the two faces of each notched beam to follow the crack opening and propagation during the test campaign (Figure 1). In addition, an LVDT sensor placed on the middle of the beam followed the evolution of the deflection at this point during the test. In parallel, a neighboring weather station provided information about the climatic conditions during the experiment. Indeed, the evolutions of Relative Humidity (RH) and Temperature $(\mathrm{T})$ are continually and automatically recorded (all the $5 \mathrm{~min}$ ) and provided by the Laboratory of physical meteorology of Clermont University, which is at $100 \mathrm{~m}$ from the experimental device, during the experimental phase. In summary, this experimental setup allows us to obtain a regular follow-up of the evolution of the following parameters: opening of crack, length of the crack, deflection and environmental conditions. Among the available data, only deflection and climate measurements will be used in this study for updating the probability of failure of the beam.

\subsection{Experimental results}

The results presented in this section concern one beam of Douglas fir that was tested until breaking from June to July 2016. The results of this beam will be used in this paper to illustrate the proposed methodology for reliability assessment and updating. Evolution of measurements (deflection $(w)$ and climate parameters ( $T$ and $R H)$ ) is shown in Figure 2. According to this figure, it is observed that in the long term the absolute value of the defection increases until the end of the experiment by a coupled interaction between creep and crack propagation processes. For short time periods, it is also noted that there are direct relationships between the cycles of $T$ and $R H$ and the deflection during the test. For example, in the period from 300 to 400 hours, the absolute value of deflection increases during drying and heating phases (Figure 2).

The experimental observations presented in this section highlighted the larger influence of climate conditions on deflection. Consequently, it is paramount to include these environmental effects combined with experimental measurements for improving reliability assessment. Since tests presented in this section are time-consuming, a comprehensive numerical model is also required for the efficient understanding of fracture phenomena subjected to mechanical and environmental loading. Such a model is able to consider only temperature effects and is summarized in section 3 . The experimental data (geometry, loading, material properties, temperature and deflection) will be used afterwards for reliability assessment purposes by considering the Bayesian framework proposed in section 4 . Particularly, temperature variations and deflection measurements will be used to update the instantaneous probability of failure (section 5). 


\section{Mixed-mode fracture formulation and numerical implementation}

This section first summarizes the mathematical formulation of the A-integral [14]; afterwards, it describes the considerations for its numerical implementation in a Finite Element Analysis (FEA) software that will be used to propagate uncertainties.

\subsection{A-integral formulation}

In order to implement the A-integral in a FEA software, it is easier to take into account a surface domain integral. Within this context, the curvilinear path is transformed into surface domain by introducing a vector field $\vec{\theta}$ as shown in Figure 3. This mapping function is continuously differentiable and takes these values: $\vec{\theta}=(1,0)$ inside the ring $\mathbf{S}$, and: $\vec{\theta}=(0,0)$ outside it, Figure 3 . Hence, the use of the Gauss-Ostrogradsky theorem $[7,14]$ enables us to obtain the following A-integral given by:

$$
\begin{gathered}
A=\int_{\Omega} \frac{1}{2}\left[\sigma_{i j, k}^{v} u_{i}-\sigma_{i j}^{u} v_{i, k}\right] \theta_{k, j} d \mathrm{~S}-\int_{\Omega} \frac{1}{2}\left[\gamma \vartheta_{i} \delta_{i j} v_{i, j k} \Delta T_{, j}\right] \theta_{k, j} d \mathrm{~S} \\
+\int_{L_{p}} \frac{1}{2} F_{i} v_{i, j} \theta_{j} d x_{1}
\end{gathered}
$$

where $F_{1}=p$ and $F_{2}=q$ represent the loads applied to the upper crack edge, and $F_{1}=-p$ and $F_{2}=-q$ the loads applied to the lower crack edge. $\sigma_{i j}^{u}$ and $\sigma_{i j}^{\vartheta}$ are stress tensor components deduced from the real displacement field $u$ and the virtual displacement field $\vartheta$, respectively. $\theta$ is a continuous and derivable scalar field. It forms a crown around the crack tip as shown in Figure 3. The factor $\gamma$ introduces the elastic modulus versus temperature variation $\Delta T$ in plane strain. For the orthotropic material, the value of $\gamma$ depends on the direction of the material, since the engineering constants are not the same for all directions. $\delta$ is the Lagrangian representation of the bilinear form of strain energy density. The first term of eq (1) is the classical term of the M $\theta$-integral [14,15], which facilitates the separation of the contribution of each fracture mode, without resorting to separate the displacement field into symmetric and antisymmetric parts. The second term of the A-integral deals with the temperature effect, including temperature gradients inducing thermal dilatation and contraction. The last term of the A-integral represents the effect of pressures $p$ and $q$ applied perpendicularly to the cracked lips, where $L_{p}$ is the integration path. Note that, the mechanical load applied on the cracked lips can be induced by fluid action or contact between the crack lips during the crack growth process. The only restriction is the non-existence of friction or shear effects in the cracked lips.

In the orthotropic case, the mechanical behavior of an anisotropic material is described by the stressstrain relationship $\epsilon_{i}=\sum_{j} E_{i j} \sigma_{i j}+\sum_{j} \alpha_{i} \Delta T$, where $E_{i j}$ are the contracted notations of the compliance tensor $S_{i j k l}$ that depend on modulus and Poisson coefficients in longitudinal, transversal, radial directions; and $\alpha_{i}$ are thermal expansion coefficients in longitudinal $\left(\alpha_{1}\right)$ and transversal $\left(\alpha_{2}\right)$ direction of wood. In the case of two-dimensional anisotropic elasticity problems, the components $\vartheta_{1}$ and $\vartheta_{2}$ of the near tip displacement field are expressed as [15]:

$$
\begin{aligned}
\vartheta_{1} & =K_{I} \sqrt{\frac{2 r}{\pi}} \Re\left[\frac{1}{\mu_{1}-\mu_{2}}\left(\mu_{1} p_{2} \sqrt{\cos \varphi+\mu_{2} \sin \varphi}-\mu_{2} p_{1} \sqrt{\cos \varphi+\mu_{1} \sin \varphi}\right)\right] \\
& +K_{I I} \sqrt{\frac{2 r}{\pi}} \Re\left[\frac{1}{\mu_{1}-\mu_{2}}\left(p_{2} \sqrt{\cos \varphi+\mu_{2} \sin \varphi}-p_{1} \sqrt{\cos \varphi+\mu_{1} \sin \varphi}\right)\right]
\end{aligned}
$$




$$
\begin{aligned}
\vartheta_{2} & =K_{I} \sqrt{\frac{2 r}{\pi}} \Re\left[\frac{1}{\mu_{1}-\mu_{2}}\left(\mu_{1} q_{2} \sqrt{\cos \varphi+\mu_{2} \sin \varphi}-\mu_{2} q_{1} \sqrt{\cos \varphi+\mu_{1} \sin \varphi}\right)\right] \\
& +K_{I I} \sqrt{\frac{2 r}{\pi}} \Re\left[\frac{1}{\mu_{1}-\mu_{2}}\left(q_{2} \sqrt{\cos \varphi+\mu_{2} \sin \varphi}-q_{1} \sqrt{\cos \varphi+\mu_{1} \sin \varphi}\right)\right]
\end{aligned}
$$

where $(r, \varphi)$ represents the polar coordinate system of a point $P_{n}$ in the neighborhood of the crack tip. $k$ is a coefficient such as $k=3-4 \vartheta$ in plane strain and $k=\frac{3-4 \vartheta}{1+\vartheta}$ in plane stress. $\mu_{1}$ and $\mu_{2}$ designate the roots of the characteristic equation, which is given in the following general form, in the case of elastic anisotropic material:

$$
\mathrm{E}_{11} \mu^{4}-2 \mathrm{E}_{16} \mu^{3}+\left(2 \mathrm{E}_{12}+\mathrm{E}_{66}\right) \mu^{2}-2 \mathrm{E}_{26} \mu+\mathrm{E}_{22}=0
$$

The parameters $p_{j}$ and $q_{j},(j=1,2)$ in eqs. (2) and (3) are given respectively by:

$$
\begin{aligned}
& p_{j}=\mathrm{E}_{11} \mu_{j}^{2}+\mathrm{E}_{12}-\mathrm{E}_{16} \mu_{j} \\
& q_{j}=\mathrm{E}_{12} \mu_{j}+\frac{\mathrm{E}_{22}}{\mu_{j}}-\mathrm{E}_{26}
\end{aligned}
$$

Knowing the material properties, the singular stress field near the crack tip can be easily obtained from the near tip displacement field defined by equation (1), and the stress-strain governing the mechanical behavior of the material.

According to the definition of the energy release rate $G$, the superposition principle $[2,15]$, the virtual stress tensor components $\sigma_{i j}^{v}$ are proportional to the virtual thermal stress intensity factors ${ }^{A} K_{I}^{v}$ and ${ }^{A} K_{I}^{v}$, which characterize the virtual open and shear modes, respectively. Moreover, the A-integral, like the M-integral, can be physically interpreted as a particular definition of real stress intensity factors ${ }^{A} K_{I}^{u}$ and ${ }^{A} K_{I I}^{u}$. The mixed-mode separation can then be obtained by performing two distinct computations of ${ }^{A} K_{I}^{u}$ and ${ }^{A} K_{I I}^{u}$ for special values of ${ }^{A} K_{I}^{v}$ and ${ }^{A} K_{I}^{v}$, such as:

$$
{ }^{A} K_{I}^{u}=8 \frac{A\left({ }^{A} K_{I}^{v}=1,{ }^{A} K_{I I}^{v}=0\right)}{C_{1}} ; \quad{ }^{A} K_{I I}^{u}=8 \frac{A\left({ }^{A} K_{I}^{v}=0,{ }^{A} K_{I I}^{v}=1\right)}{C_{2}}
$$

where $C_{1}$ and $C_{2}$ indicate the reduced elastic compliances in the opening and shear modes, respectively. The thermal energy release rates, in each specific fracture mode ${ }^{A} G_{I}$ and ${ }^{A} G_{I I}$, are ultimately given by the following expression:

$$
{ }^{A} G_{I}=C_{1} \frac{\left({ }^{A} K_{I}^{u}\right)^{2}}{8} \text { and }{ }^{A} G_{I I}=C_{2} \frac{\left({ }^{A} K_{I I}^{u}\right)^{2}}{8}
$$

${ }^{A} G_{I}$ and ${ }^{A} G_{I I}$ will be used in section 4 in the reliability analysis to determine the probability of failure.

\subsection{Numerical implementation}

Figure 4 summarizes the steps followed to estimate fracture parameters and deflection based on the implementation of the A-integral procedure in a FEA software. The process starts with a fine mesh at the vicinity of the cracks. Two procedures are after launched in parallel after assigning material properties and boundary and loading conditions. They aim at estimating real and auxiliary mechanical fields that are finally used to determine the fracture parameters and deflection at the interest points. 
The A-integral formulation described previously was numerically implemented in the FEA software Cast $3 \mathrm{~m}$. FEA was applied to model the notched timber beam subjected to the static concentrate loads and environmental conditions described in section 2 (Figure 1). Taking into account the symmetry of the problem and to reduce the computational effort, we modeled one half of the notched beam subjected to one concentrate load (Figure 5). Note that the density of the mesh increases at the vicinity of the crack. The numerical model of the cracked beam accounts for the same geometry, load and material properties than the real timber beam. These similar conditions will allow us to integrate experimental data for structural reliability updating (section 4).

The input parameters (geometry, load and material properties of the beam) for the FEA are presented in Table 1. It is supposed that the timber fibers are oriented horizontally. Table 1 also includes the random variables considered in the study $\left(P, E_{1}, E_{2}\right.$, and $\left.G_{12}\right)$. We assumed that the applied load follow a normal $(\mathrm{N})$ distribution with a mean value $(\mu)$ estimated according to the theoretical weight of the concrete blocks and considering a coefficient of variation (COV) of $10 \%$. We considered that the timber material properties $\left(E_{1}, E_{2}\right.$, and $\left.G_{12}\right)$ follow a lognormal $(\mathrm{LN})$ distribution based on the recommendations provided in [19]. Their mean values and coefficients of variations were defined based on experimental tests for the Douglas Fir specie used in the experiment. With respect to the values or COV given in [19] (0.13 for all parameters), we found a larger variability on the assessment of the longitudinal modulus for this specie. The other deterministic parameters reported in Table 1 were also determined from the experimental campaign carried out within the framework of the CLIMBOIS project.

\section{Uncertainty propagation and failure probability updating}

\subsection{Reliability analysis}

The reliability analysis consists of computing the probability of failure under prescribed loading conditions [30,31]. The failure condition is defined by the limit state function $g(\mathbf{X})$ separating the operating space into two regions: the safe domain, where $g(\mathbf{X})>0$; and the failure domain where $g(\mathbf{X}) \leq 0$. In this study, the reliability analysis is carried out with respect to a crack propagation criterion defined as [32]:

$$
g(\mathbf{X})=1-\left(\frac{{ }^{A} G_{I}(\mathbf{X})}{G_{I c}}+\frac{{ }^{A} G_{I I}(\mathbf{X})}{G_{I I c}}\right)
$$

where $G_{I C}$ and $G_{I I c}$ are the critical energy release rates for modes I and II, respectively, obtained by testing (deterministic values in Table 1); ${ }^{A} G_{I}(\mathbf{X})$ and ${ }^{A} G_{I I}(\mathbf{X})$ are the applied energy release rates for these two cracking modes due to external loading obtained by solving the formulations described in section 3; and $\mathbf{X}$ is the vector of random variables (e.g., $P, E_{1}, E_{2}$, and $G_{12}$ in Table 1). This study assumes that the strength variables, $G_{I C}$ and $G_{I I c}$, are independent of the loading variables, ${ }^{A} G_{I}(\mathbf{X})$ and ${ }^{A} G_{I I}(\mathbf{X})$. For this limit state function, the probability of failure, $p_{f}$, indicates that crack propagation started and is evaluated by integrating the joint density function of the random variables $f(\mathbf{X})$ over the failure domain:

$$
p_{f}=P[g(\mathbf{X}) \leq 0]=\int_{g(\mathbf{X}) \leq 0} f(\mathbf{X}) d \mathbf{X}
$$

The evaluation of the above integral becomes a numerical challenge because of the complexity of the mechanical models described section 3. In addition, as one of the aims of this paper is to update the failure probability from real data, we develop the Bayesian Network framework described in the following section that is able to deal with both aspects. 


\subsection{Bayesian Network modeling}

\subsubsection{Basics of $B N$}

$\mathrm{BN}$ is Direct Acyclic Graph (DAG) consisting of a set of nodes (parents and children) that are connected by edges to illustrate their dependencies. Nodes in BN are graphical representations of objects and events that exist in the real world and can be modeled as continuous or discrete random variables. A conditional Probability Density Function (PDF), $f(X \mid \mathbf{p a}(X))$ or Probability Mass Function (PMF), $p(X \mid \mathbf{p a}(X))$ is assigned to each child node, where $\mathbf{p a}(X)$ are the parents of $X$ in the DAG. An edge may represent causal relationships between the variables (nodes) but this is not a requirement. The graphical structure of a $\mathrm{BN}$ encodes conditional independence assumption among the random variables. Hence, a BN is a compact model representing the joint PDF or PMF among random variables. In this study, only BNs with discrete random variables are considered. Figure 6 illustrates a simple BN that consists of three nodes representing three discrete random variables $X_{1}, X_{2}$ and $X_{3}$ in which $X_{2}$ and $X_{3}$ are children of the parent node $X_{1}$. For each node in the BN, its PMF defines conditional dependences on its parents and the joint PMF of the BN presented in Figure 6 is formed as a product of these conditional probabilities:

$$
P\left(X_{1}, X_{2}, X_{3}\right)=P\left(X_{1}\right) P\left(X_{2} \mid X_{1}\right) P\left(X_{3} \mid X_{1}\right)
$$

where $P\left(X_{i} \mid X_{j}\right)$ denotes the conditional probability of $X_{i}$ given $X_{j}$.

BNs allow introducing new information (evidences) from the observed nodes to update the probabilities in the network. For example, if we have some evidences $o$ to introduce to node $X_{2}$ $\left(X_{2}=o\right)$, this information propagates through the network and the joint PMF of the two other nodes can be recalculated as:

$$
P\left(X_{1}, X_{2} \mid o\right)=\frac{P\left(X_{1}, o, X_{3}\right)}{P(o)}=\frac{P\left(X_{1}\right) \mathrm{P}\left(o \mid X_{1}\right) \mathrm{P}\left(X_{3} \mid X_{1}\right)}{\sum_{X_{1}} P\left(X_{1}\right) \mathrm{P}\left(o \mid X_{1}\right)}
$$

\subsubsection{BN configurations for reliability assessment and updating}

This section describes the proposed methodology for reliability assessment and updating of timber structures that combines mechanical and probabilistic methods (Figure 7). A FEA on Cast3m is used for modeling the cracked timber beam subjected to external random loads $P$ according to the formulations presented in section 3. In order to propagate uncertainties throughout the FEA, random inputs were generated from 10,000 Latin Hypercube based simulations for each random variable. The outputs of the FEA are the deflection at the middle of the timber beam $w$, the release energy rates $\left({ }^{A} G_{I}(\mathbf{X})\right.$ and $\left.{ }^{A} G_{I I}(\mathbf{X})\right)$ and the evaluation of the limit state $g(\mathbf{X})$. The input and output simulations are used to construct the BN presented in Figure 7 that can be used to estimate and update the structural reliability from deflection and temperature measurements.

The BN configuration representing for the performance of the timber beam is described in Figure 7 . The random input parameters $\left(E_{1}, E_{2}, G_{12}\right.$, and $\left.P\right)$ and the outdoor temperature $T$ are modeled as parent nodes. Note that the initial temperature $\left(T_{0}\right)$ necessary to estimate the temperature gradient $\Delta T=T-T_{0}$ in eq. (1), is assumed to be the mean value of temperature during the exposure time. The outputs from FEA processing $\left(w,{ }^{A} G_{I}\right.$ and $\left.{ }^{A} G_{I I}\right)$ and the limit state are the child nodes. The relationships between child and parent nodes are defined by Conditional Probability Tables (CPTs). For example, node $w$ (deflection) is the child node of its five parent nodes $\left(E_{1}, E_{2}, G_{12}, P\right.$ and $\left.T\right)$; therefore its CPT is defined by $p\left(w \mid E_{1}, E_{2}, G_{12}, P, T\right)$. Input and output data from simulations are used to estimate the CPTs for all child nodes. Once the BN is constructed, it allows introducing observations at some nodes to update probabilities of other nodes. With assumption that all nodes are discrete, the probability of deflection $p(w)$ is given by: 


$$
p(w)=p\left(w \mid E_{1}, E_{2}, G_{12}, P, T\right) p\left(E_{1}, E_{2}, G_{12}, P, T\right)
$$

By considering that $E_{1}, E_{2}, G_{12}, P$ and $T$ are independent variables, the joint probability of $E_{1}, E_{2}$, $G_{12}, P$ and $T$ can be rewritten as $p\left(E_{1}, E_{2}, G_{12}, P, T\right)=p\left(E_{1}\right) p\left(E_{2}\right) p\left(G_{12}\right) p(P) p(T)$. The joint probability mass function of $\mathrm{BN}$ defined in Figure 7 can be written as follows:

$$
\begin{aligned}
& p\left(E_{1}, E_{2}, G_{12}, P, T, w,{ }^{A} G_{I},{ }^{A} G_{I I}, g\right) \\
& =p\left(w \mid E_{1}, E_{2}, G_{12}, P, T\right) p\left({ }^{A} G_{I} \mid E_{1}, E_{2}, G_{12}, P, T\right) p\left({ }^{A} G_{I I} \mid E_{1}, E_{2}, G_{12}, P, T\right) p\left(\mathrm{~g} \mid{ }^{A} G_{I},{ }^{A} G_{I I}\right)
\end{aligned}
$$

Let us focus on how to use experimental data for updating the distribution of parent nodes. For example for $E_{1}$, assuming that we have observations of deflection that will be introduced at node $w$, we aim at computing the a posteriori distribution $p\left(E_{1} \mid w\right)$ as:

$$
p\left(E_{1} \mid w\right)=\sum_{E_{2}, G_{12}, P, T} p\left(E_{1}, E_{2}, G_{12}, P, T \mid w\right)
$$

where:

$$
\sum p\left(E_{1}, E_{2}, G_{12}, P, T \mid w\right)=\frac{p\left(E_{1}, E_{2}, G_{12}, P, T, w\right)}{p(w)}
$$

Then a posteriori of node $E_{1}$ is determined by marginalising the joint probability in Eq. (14) to obtain the joint distribution of the subsets of variables:

$$
p\left(E_{1}, E_{2}, G_{12}, P, T, w\right)=\sum_{{ }_{G_{I}},{ }_{G_{I I}}, g} p\left(E_{1}, E_{2}, G_{12}, P, T, w,{ }^{A} G_{I},{ }^{A} G_{I I}, g\right)
$$

The posteriori distributions of other parent nodes can be computed by similar calculations. After updating BNs, statistical moments (mean, standard deviation) of interest nodes could be determined from their posterior distributions.

We only consider in this study nodes discretized into a number of finite states. Table 2 presents the discretization of nodes in the BN. Each node is divided into a number of states in pre-defined boundaries. The boundaries should be large enough to cover most part of possible values. The number of states could be adjusted to obtain more accurate results. For example, temperature $(T)$ and deflection have more states (20 and 30 states, respectively) than other nodes (10 states) to be able to capture the effects of small changes in observed values.

\section{Results}

The first past of this section starts presenting the results of a deterministic study of the influence of temperature variations on the fracture parameters, deflection and limit state function (section 5.1). After propagating uncertainties into the mechanical model, section 5.2 discuses the effects of accounting temperature variations on the assessment of the probability of failure. Section 5.3 performs a sensitivity analysis focusing on studying the influence of introducing several evidences for updating the BN outputs of interest. Finally, the results of failure probability updating with real data are presented and discussed in section 5.4.

\subsection{Deterministic influence of temperature}

This section studies the effects of temperature on release energy rates, deflection and limit state function (eq. (9)). Input random variables $\left(E_{1}, E_{2}, G_{12}\right.$, and $\left.P\right)$ in Table 1 are considered as deterministic parameters by fixing their values to their corresponding means. Figure 8 presents the influence of the temperature gradient $\Delta T$ on the release energy rates $\left({ }^{A} G_{I}\right.$ and $\left.{ }^{A} G_{I I}\right)$ with different 
initial temperatures $\left(T_{0}\right)$. It is noted that an increase in $\Delta T$ can lead to larger release energy rate in modes I and II (Figure 8a). For example, rising $\Delta T$ by $10^{\circ} \mathrm{C}$ (from $0^{\circ} \mathrm{C}$ to $10^{\circ} \mathrm{C}$ ), values of ${ }^{A} G_{I}$ and ${ }^{A} G_{I I}$ can increase up to $10 \%$. On the other hand, initial temperature $\left(T_{0}\right)$ gives an opposite trend but with less influence. When $T_{0}$ varies from $0{ }^{\circ} \mathrm{C}$ to $30^{\circ} \mathrm{C}$, values of ${ }^{A} G_{I}$ and ${ }^{A} G_{I I}$ reveal a reduction of less than $3 \%$. Hence, the influence of initial temperature on ${ }^{A} G_{I}$ and ${ }^{A} G_{I I}$ could be neglected.

Figure 9a presents the relationship between temperature and deflection for the beam. It is observed that when the temperature variation increases, the beam deflection is reduced. This behavior can be related to the thermal expansion of the whole beam and was also observed experimentally in Figure 2. By comparing the experimental deflection at the beginning of the experiment (Figure 2) with the presented in Figure 9a, it can be noticed that the order of magnitude in both cases is very close.

The effects of $\Delta T$ on ${ }^{A} G_{I}$ and ${ }^{A} G_{I I}$ explain the dependency of the limit state function (eq. (9)) on the beam on the outdoor temperature variation (Figure $9 \mathrm{a}$ ) where higher temperature variation will lead to smaller values of limit state. As a result, the probability of failure $\left(p_{f}\right)$ defined from this limit state will increase for larger $\Delta T$.

\subsection{Assessment of prior failure probability}

Table 3 presents the prior mean values of deflection, energy release rates and failure probability calculated from BN. Two cases are investigated corresponding to the A-integral without temperature effects and A-integral with $\Delta T=10^{\circ} \mathrm{C}$. For both cases $\Delta T$ is considered as deterministic and therefore the $\mathrm{BN}$ used to estimate these results did not include temperature as a parent node. As discussed in previous section, by introducing a temperature variation of $10^{\circ} \mathrm{C}$, the deflection of the beam decreases meanwhile the release energy rates in both modes increases significantly. This temperature variation increases the probability of failure by almost twice with respect to the case where $\Delta T=0^{\circ} \mathrm{C}$. It is also worth noting that by introducing the uncertainties the prior mean values of $w,{ }^{A} G_{I}$ and ${ }^{A} G_{I I}$ are higher than those obtained from deterministic approach (section 5.1). For example, with $\Delta T=0^{\circ} \mathrm{C}$, the deflection without uncertainty is about $-11.33 \mathrm{~mm}$ (Figure 9a) which is lower than the value presented in Table 3. These differences are related to the non-linear propagation of uncertainties throughout the mechanical model.

\subsection{Sensitivity analysis of updating values}

This section studies the sensitivity of the BN when it is updated with different evidences. We consider seven cases presented in Table 4. For each case, the evidence introduced at the studied node is $10 \%$ higher or smaller than its mean prior values. This sensitivity study does not consider combined effects of several parameters at the same time. The sensitivity analysis will focus on the updated values of the outputs $\left(w,{ }^{A} G_{I},{ }^{A} G_{I I}\right.$, and $\left.p_{f}\right)$ and the relative errors with respect to their prior values.

By updating the $\mathrm{BN}$ by a value of $E_{1}$ increased $10 \%$ with respect to its mean value (case 1 ), the deflection of the beam decreases $7 \%$ (Table 4). This trend is expected because in the mechanical behavior, the defection of the beam is reduced when the longitudinal modulus $\left(E_{1}\right)$ increases. Larger values of the longitudinal modulus reduce the release energy rates and therefore the probability of failure but at low level.

On the other hand, transversal modulus has more influence on the mechanical behavior of the cracked beam (Table 4). An increase of $E_{2}$ by $10 \%$ leads to an approximately $10 \%$ reduction of release energy in both modes and more than $90 \%$ reduction of $p_{f}$ (case 2). This is because the transversal modulus makes a large contribution in creating a crack edge in $x y$-plane. Moreover, it is obvious that $E_{2}$ almost has no influence on the deflection in the $x y$-plane.

In case 3 , increasing shear modulus $\left(G_{12}\right)$ has more influence on the cracking behavior in mode II (shear mode) by a decreasing of ${ }^{A} G_{I I}$ by about $4 \%$ (Table 4). The shear modulus also impacts the 
deflection and cracking in mode I (open mode) but at a low level, being only $1.4 \%$ of reduction for each parameter.

It is clear that the load $(P)$ has important influence on both deflection and cracking (Table 4). In case 4, when $P$ increases by $10 \%$, all the output parameters $\left(w,{ }^{A} G_{I},{ }^{A} G_{I I}\right.$, and $\left.p_{f}\right)$ reveal important increases by $7 \%, 16 \%, 15 \%$ and $25 \%$ respectively. An opposite trend is observed when the load decreases by $10 \%$ in case 6 .

In case 5 and case 7 , we study the dependence between deflection and cracking mechanisms for the beam (Table 4). An increasing in the deflection will lead to higher values of release energy rates in both modes and vice versa. These findings justify that the $\mathrm{BN}$ is able to represent the mechanical behavior for updating purposes; consequently, their implementation is of interest for further applications in this study when the deflection is used for updating the reliability of the timber beam.

\subsection{Updating of instantaneous failure probability}

This section presents the results of the failure probability updating of the timber beam presented in section 1 from measurement data. The reliability of the timber beam is evaluated from the limit state function defined in eq. (9), which is based on the release energy rates in modes I and II. In real practice, these two parameters are difficult to obtain; hence, the alternative approach is to update the reliability of the timber beam from other parameters that are easy to measure (temperature, deflection). During the experiment, temperature and deflection were automatically recorded for every 5 minutes (section 1). The values used for updating purposes correspond to the averages of measurements during 1 hour. Figure 1 provided the variation of temperature and deflection during 689 hours of experiment. It can be seen that the temperature reveals a large fluctuation meanwhile the deflection shows an increasing trend with smaller variation during the experiment. The instantaneous probability of failure of the beam will be updated every hour by introducing the observations of temperature and deflection into the BN shown in Figure 7. This section will analyze first the effects of updating temperature and deflection separately to finalize studying the combined effect of updating both parameters.

Figure 10a presents the updating of instantaneous $p_{f}$ with evidences from temperature measurements only. The initial temperature $\left(T_{0}\right)$, which is the average temperature during the experiment, is $21^{\circ} \mathrm{C}$. Therefore, temperature variation varies within the range $\Delta T=\left[-11^{\circ} \mathrm{C} ; 16^{\circ} \mathrm{C}\right]$. It can be seen that the temperature variation during the test is considerable large, however its influence on reliability is relatively low as observed in Figure 10a. The maximum value of $p_{f}(0.06)$ is obtained at 608 hours of experiment where the temperature reached its maximum value $\left(37^{\circ} \mathrm{C}\right)$. During the experiment, the updated values of $p_{f}$ are lower during the periods with small temperature (e.g., periods of (180h; $240 \mathrm{~h})$ and $(420 \mathrm{~h} ; 520 \mathrm{~h})$ ) and vice versa. This trend is due to the dependency between temperature and cracking mechanisms which was previously analyzed from FEA in section 5.1.

On the other hand, Figure $10 \mathrm{~b}$ shows that deflection variations have more influence on reliability of the beam. The maximum updated instantaneous $p_{f}$ in this case was 0.016 . The evolution of $p_{f}$ follows an increasing trend in accordance with the rise in deflection measured during the experiment. The variation of deflection is small leading to the same values of $p_{f}$ obtained for some periods of experiments. For example, the same reliability of the beam was obtained $\left(p_{f}=0.1\right)$ during period of $(260 \mathrm{~h} ; 360 \mathrm{~h})$ when the deflection varies in the range $(15 ; 15.7) \mathrm{mm}$. For such small variations, the obtained observations during that period will correspond to the same states of deflection node in BN leading to the same updated values.

Figure 11 depicts the instantaneous probability of failure updated with temperature and deflection measurements. This combination leads to higher values of $p_{f}$ if the observations provide larger values of temperature and an increasing trend for deflection. For example, during the periods $(320 \mathrm{~h} ; 400 \mathrm{~h})$ and $(540 \mathrm{~h} ; 660)$, the maximum values of $p_{f}$ are about 0.2 and 0.35 respectively, which are higher than those obtained when only a single parameter was updated (Figure 10). In periods with low temperature 
(e.g., (180h; 240h); $(420 \mathrm{~h} ; 520 \mathrm{~h}))$, the instantaneous probability of failure is lower than the obtained when updating from deflection data only due to the effect of temperature. Therefore, it can be concluded that the updated values of $p_{f}$ are in accordance with observation data and the proposed methodology is useful to update reliability of the timber beam from measurements.

\section{Conclusions}

This paper proposed a methodology for reliability assessment and updating of notched timber components. It combines mechanical (A-integral formulation) and probabilistic (simulations and $\mathrm{BN}$ ) approaches and it is able to represent in a simplified manner the structural performance of timber structures for a reliability analysis. The methodology was illustrated and tested with data obtained from a notched beam subjected to constant loading and outdoor environmental exposure. The experimental observations indicated that the deflection of the beam increases with time and is affected by outdoor environmental conditions. Deterministic and probabilistic studies based respectively on the numerical A-integral implementation and the BN also confirmed these relationships and highlighted the helpfulness of using measurements of temperature and deflection for reliability updating purposes.

One of the limitations of this study is the use of a point-in-time analysis that provides the instantaneous probability of failure that neglects the history of the environmental and mechanical loading. Further developments of the A-integral formulation will include these time-dependent aspects and dynamic Bayesian networks could be used in future studies to overcome this limitation and improve the assessment and updating of time-dependent failure probability. A second aspect for the improvement of the proposed methodology will be the consideration of moisture variation effects. New mechanical models (that include crack propagation and moisture variation effects) are still under development. In addition, new experiments are being done to obtain additional experimental data. These models and data will be very useful to validate and improve the methodology for reliability assessment and updating.

\section{Acknowledgements}

The authors would like to acknowledge the financial support of project CLIMBOIS ANR-13-JS090003-01 as well as the labelling of the ViaMéca French cluster.

\section{References}

[1] Ranjith S, Setunge S. Deterioration Prediction of Timber Bridge Elements Using the Markov Chain. Journal of Performance of Constructed Facilities 2011;27:319-25. doi:10.1061/(ASCE)CF.1943-5509.0000311.

[2] Riahi H, Moutou Pitti R, Dubois F, Chateauneuf A. Mixed-mode fracture analysis combining mechanical, thermal and hydrological effects in an isotropic and orthotropic material by means of invariant integrals. Theoretical and Applied Fracture Mechanics 2016;85:424-34. doi:10.1016/j.tafmec.2016.06.002.

[3] Toussaint E, Fournely E, Moutou Pitti R, Grédiac M. Studying the mechanical behavior of notched wood beams using full-field measurements. Engineering Structures 2016;113:277-86. doi:10.1016/j.engstruct.2016.01.052.

[4] Frühwald Hansson E. Analysis of structural failures in timber structures: Typical causes for failure and failure modes. Engineering Structures 2011;33:2978-82. doi:10.1016/j.engstruct.2011.02.045.

[5] Pambou Nziengui CF, Moutou Pitti R, Ikogou S. Impact of cyclic compressive loading and moisture content on the mechanical behavior of Aucoumea Klaineana Pierre. Wood Material Science \& Engineering 2017. doi:10.1080/17480272.2017.1307281.

[6] Teodorescu I, Țăpuşi D, Erbaşu R, Bastidas-Arteaga E, Aoues Y, Țăpuşi D, et al. Influence of the Climatic Changes on Wood Structures Behaviour. vol. 112. 2017. doi:10.1016/j.egypro.2017.03.1112.

[7] Dubois F, Moutou-pitti R, Husson J. Thermodynamic approach about fracture modeling under mechano-sorptive loading. SEM Annual Conference, New Mexico, USA: 2009.

[8] Pambou Nziengui CF, Moutou Pitti R, Fournely E. Environmental impact on crack propagation of biobased building materials: application to Abies Alba Mil. COST ACTION FP1303, Workshop / Management Committee Meeting, 
Sofia, Bulgaria 28th February - 1st March 2017: 2017.

[9] Attigui M, Petit C. Mixed-mode separation in dynamic fracture mechanics: New path independent integrals. International Journal of Fracture 1997;84:19-36. doi:10.1023/A:1007358701493.

[10] Dubois F, Randriambololona H, Petit C. Creep in Wood Under Variable Climate Conditions: Numerical Modeling and Experimental Validation. Mechanics of Time-Dependent Materials 2005;9:173-202. doi:10.1007/s11043-0051083-z.

[11] Rice JR. A Path Independent Integral and the Approximate Analysis of Strain Concentration by Notches and Cracks. Journal of Applied Mechanics 1968;35:379. doi:10.1115/1.3601206.

[12] Noether E. Invariant variation problems. Transport Theory and Statistical Physics 1971;1:186-207. doi:10.1080/00411457108231446.

[13] Chen FHK, Shield RT. Conservation laws in elasticity of the J-integral type. Zeitschrift Für Angewandte Mathematik Und Physik ZAMP 1977;28:1-22. doi:10.1007/BF01590704.

[14] Moutou Pitti R, Dubois F, Petit C. Generalization of T and A integrals to time-dependent materials: analytical formulations. International Journal of Fracture 2010;161:187-98. doi:10.1007/s10704-010-9453-1.

[15] Hamdi SE, Moutou Pitti R, Dubois F. Temperature variation effect on crack growth in orthotropic medium: Finite element formulation for the viscoelastic behavior in thermal cracked wood-based materials. International Journal of Solids and Structures 2016; In press. doi:10.1016/j.ijsolstr.2016.09.019.

[16] Brites RD, Neves LC, Saporiti Machado J, Lourenço PB, Sousa HS. Reliability analysis of a timber truss system subjected to decay. Engineering Structures 2013;46:184-92. doi:10.1016/j.engstruct.2012.07.022.

[17] Ryan PC, Stewart MG, Spencer N, Li Y. Reliability assessment of power pole infrastructure incorporating deterioration and network maintenance. Reliability Engineering \& System Safety 2014;132:261-73. doi:10.1016/j.ress.2014.07.019.

[18] Lourenço PB, Sousa HS, Brites RD, Neves LC. In situ measured cross section geometry of old timber structures and its influence on structural safety. Materials and Structures 2012;46:1193-208. doi:10.1617/s11527-012-9964-5.

[19] Köhler J, Sørensen JD, Faber MH. Probabilistic modeling of timber structures. Structural Safety 2007;29:255-67. doi:10.1016/j.strusafe.2006.07.007.

[20] Kohler J, Svensson S. Probabilistic representation of duration of load effects in timber structures. Engineering Structures 2011;33:462-7. doi:10.1016/j.engstruct.2010.11.002.

[21] Sørensen JD. Framework for robustness assessment of timber structures. Engineering Structures 2011;33:3087-92. doi:10.1016/j.engstruct.2011.02.025.

[22] Kirkegaard PH, Sørensen JD, Čizmar D, Rajčić V. System reliability of timber structures with ductile behaviour. Engineering Structures 2011;33:3093-8. doi:10.1016/j.engstruct.2011.03.011.

[23] Salman AM, Li Y, Bastidas-Arteaga E. Maintenance optimization for power distribution systems subjected to hurricane hazard, timber decay and climate change 2017;168. doi:10.1016/j.ress.2017.03.002.

[24] Sousa HS, Sorensen JD, Kirkegaard PH, Branco JM, Lourenço PB. On the use of NDT data for reliability-based assessment of existing timber structures. Engineering Structures 2013;56:298-311. doi:10.1016/j.engstruct.2013.05.014.

[25] Tran TB, Bastidas-Arteaga E, Schoefs F. Improved Bayesian network configurations for probabilistic identification of degradation mechanisms: application to chloride ingress. Structure and Infrastructure Engineering 2016;12:116276. doi:10.1080/15732479.2015.1086387.

[26] Tran T-B, Bastidas-Arteaga E, Schoefs F. Improved Bayesian network configurations for random variable identification of concrete chlorination models. Materials and Structures 2016;49:4705-4718. doi:10.1617/s11527016-0818-4

[27] Ma Y, Wang L, Zhang J, Xiang Y, Liu Y. Bridge Remaining Strength Prediction Integrated with Bayesian Network and In Situ Load Testing. Journal of Bridge Engineering ASCE 2014;19:1-11. doi:10.1061/(ASCE)BE.19435592.0000611 . 
[28] Tran T-B, Bastidas-Arteaga E, Schoefs F, Bonnet S. A Bayesian network framework for statistical characterisation of model parameters from accelerated tests: application to chloride ingress into concrete. Structure and Infrastructure Engineering 2017;In Press:1-14. doi:10.1080/15732479.2017.1377737.

[29] NF-EN 1995. Eurocode 5: design of timber structure, Part 1-1 General rules and rules for buildings, Final draft prEN 1995-1-1, Brussels, European Comitee for Standardization. 2005.

[30] Lemaire M, Chateauneuf A, Mitteau J-C. Structural Reliability. Wiley; 2009.

[31] Sánchez-Silva M, Klutke G-A. Reliability and Life-Cycle Analysis of Deteriorating Systems. Cham: Springer International Publishing; 2016. doi:10.1007/978-3-319-20946-3.

[32] Moutou Pitti R, Chateauneuf A. Statistical and reliability analysis for mixed-mode fracture tests applied to wood material. Wood Science and Technology 2012;46:1099-112. doi:10.1007/s00226-011-0462-7. 


\section{List of tables}

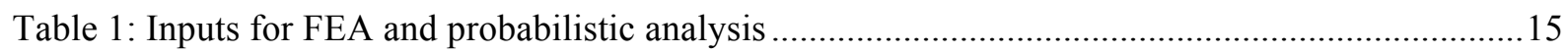

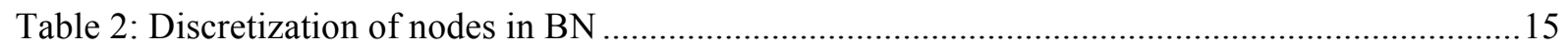

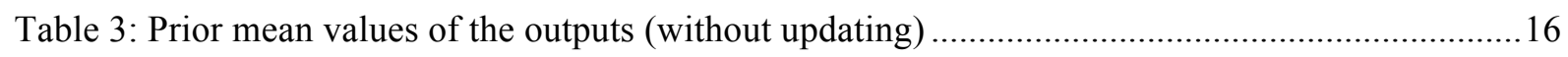

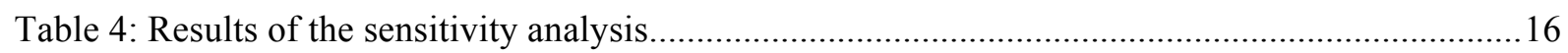

\section{List of figures}

Figure 1: Notched Douglas fir and experimental setup description..................................................17

Figure 2: Recorded evolutions of deflection, temperature and relative humidity.................................18

Figure 3: Integration domain $S$ on the notched beam and definition of the vector field $\theta \ldots \ldots \ldots \ldots \ldots \ldots \ldots . . .18$

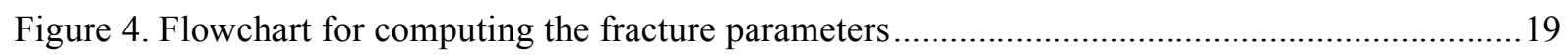

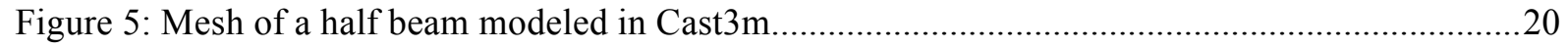

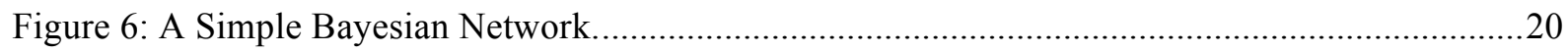

Figure 7: Combined mechanical and probabilistic methods used for reliability assessment and

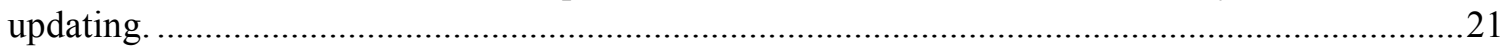

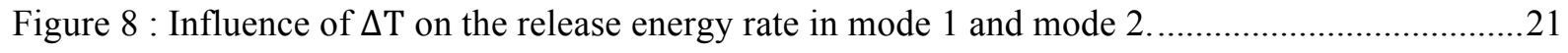

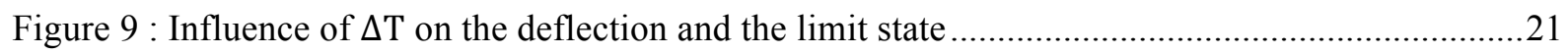

Figure 10: Updating of instantaneous probability of failure with evidences from: (a) Temperature variations only; (b) Deflection variations only

Figure 11: Updating of instantaneous probability of failure with evidences from temperature and deflection. 
Table 1: Inputs for FEA and probabilistic analysis

\begin{tabular}{lllr}
\hline Input & Parameter & Description & Value \\
\hline$L(\mathrm{~mm})$ & Length of the beam & 3,900 \\
Geometry & $H(\mathrm{~mm})$ & Height of the beam & 180 \\
& $b(\mathrm{~mm})$ & Width of the beam & $\mathrm{N}(\mu=4150 ; \mathrm{COV}=0.1)$ \\
\hline Load & $P(\mathrm{~N})$ & Concentrate load & $\mathrm{LN}\left(\mu=13 \cdot 10^{3} ; \mathrm{COV}=0.2\right)$ \\
\hline$E_{1}(\mathrm{MPa})$ & Longitudinal modulus & $\mathrm{LN}(\mu=650 ; \mathrm{COV}=0.15)$ \\
$E_{2}(\mathrm{MPa})$ & Transversal modulus & 1,000 \\
$E_{3}(\mathrm{MPa})$ & Radial modulus & $\mathrm{LN}(\mu=745 ; \mathrm{COV}=0.15)$ \\
$G_{12}(\mathrm{MPa})$ & Shear modulus & 0.42 \\
$v_{12}$ & Tangential Poisson coefficient & 0.38 \\
$v_{13}$ & Radial Poisson coefficient & 0.31 \\
$v_{23}$ & Poisson coefficient in transverse plane & $2 \times 10^{-6}$ \\
$\alpha_{1}(1 / \mathrm{K})$ & Longitudinal thermal expansion & $5 \times 10^{-5}$ \\
$\alpha_{2}(1 / \mathrm{K})$ & Coefficient & Transversal thermal expansion coefficient & 0.42 \\
$G_{I c}(\mathrm{~N} / \mathrm{mm})$ & Critical release energy in mode I & 2.52 \\
$G_{I I c}(\mathrm{~N} / \mathrm{mm})$ & Critical release energy in mode II &
\end{tabular}

Table 2: Discretization of nodes in BN

\begin{tabular}{llcl}
\hline Nodes & Prior distribution & $\begin{array}{c}\text { Number of } \\
\text { states }\end{array}$ & Boundaries \\
\hline$E_{1}(\mathrm{MPa})$ & $\mathrm{LN}\left(\mu=13 \times 10^{3} ; \mathrm{COV}=0.2\right)$ & 10 & {$[0.5 ; 3] \times 10^{4}$} \\
$E_{2}(\mathrm{MPa})$ & $\mathrm{LN}(\mu=650 ; \mathrm{COV}=0.15)$ & 10 & {$[3 ; 12] \times 10^{2}$} \\
$G_{12}(\mathrm{MPa})$ & $\mathrm{LN}(\mu=745 ; \mathrm{COV}=0.15)$ & 10 & {$[3 ; 14] \times 10^{2}$} \\
$P(\mathrm{~N})$ & $\mathrm{N}(\mu=4150 ; \mathrm{COV}=0.1)$ & 10 & {$[2 ; 7] \times 10^{3}$} \\
$T\left({ }^{\circ} \mathrm{C}\right)$ & $\mathrm{Uniform}(10 ; 40)$ & 20 & {$[10 ; 40]$} \\
${ }^{w}(\mathrm{~mm})$ & - & 30 & {$[-30 ; 0]$} \\
${ }^{A} G_{I}(\mathrm{~N} / \mathrm{mm})$ & - & 10 & {$[0 ; 0.5]$} \\
${ }^{A} G_{I I}(\mathrm{~N} / \mathrm{mm})$ & - & 10 & {$[0 ; 2] \times 10^{2}$} \\
$g$ & - & Binary & - \\
\hline
\end{tabular}


Table 3: Prior mean values of the outputs (without updating)

\begin{tabular}{ccccc}
\hline$\Delta T\left({ }^{\circ} \mathrm{C}\right)$ & $w(\mathrm{~mm})$ & ${ }^{A} G_{I}(\mathrm{~N} / \mathrm{mm})$ & ${ }^{A} G_{I I}(\mathrm{~N} / \mathrm{mm})$ & $p_{f}$ \\
\hline 0 & -11.798 & 0.159 & 0.760 & 0.031 \\
10 & -11.752 & 0.169 & 0.830 & 0.062 \\
\hline
\end{tabular}

Table 4: Results of the sensitivity analysis

\begin{tabular}{|c|c|c|c|c|c|c|c|c|c|}
\hline \multirow[b]{2}{*}{ Case } & \multirow[b]{2}{*}{ Description } & \multicolumn{4}{|c|}{ Mean values } & \multicolumn{4}{|c|}{ Sensitivity (relative error) } \\
\hline & & $\begin{array}{c}w \\
(\mathrm{~mm})\end{array}$ & $\begin{array}{c}{ }^{A} G_{I} \\
(\mathrm{~N} / \mathrm{mm})\end{array}$ & $\begin{array}{c}{ }^{A} G_{I I} \\
(\mathrm{~N} / \mathrm{mm})\end{array}$ & $p_{f}$ & $\begin{array}{c}w \\
(\mathrm{~mm})\end{array}$ & $\begin{array}{c}{ }^{A} G_{I} \\
(\mathrm{~N} / \mathrm{mm})\end{array}$ & $\begin{array}{c}{ }^{A} G_{I I} \\
(\mathrm{~N} / \mathrm{mm})\end{array}$ & $p_{f}$ \\
\hline Prior & Prior values & -11.79 & 0.1577 & 0.7535 & $2.76 \times 10^{-2}$ & - & - & - & - \\
\hline Case 1 & $+10 \% E_{1}$ & -10.97 & 0.1540 & 0.7535 & $2.61 \times 10^{-2}$ & $-7 \%$ & $-2 \%$ & $0 \%$ & $-5 \%$ \\
\hline Case 2 & $+10 \% E_{2}$ & -11.75 & 0.1420 & 0.6653 & $1.50 \times 10^{-3}$ & $-0.3 \%$ & $-10.0 \%$ & $-11.7 \%$ & $-94.6 \%$ \\
\hline Case 3 & $+10 \% G_{12}$ & -11.63 & 0.1555 & 0.7225 & $1.50 \times 10^{-2}$ & $-1.4 \%$ & $-1.4 \%$ & $-4.1 \%$ & $-45.7 \%$ \\
\hline Case 4 & $+10 \% P$ & -12.66 & 0.1829 & 0.8676 & $3.44 \times 10^{-2}$ & $7.4 \%$ & $16.0 \%$ & $15.1 \%$ & $24.6 \%$ \\
\hline Case 5 & $+10 \% w$ & - & 0.1727 & 0.8007 & $4.85 \times 10^{-2}$ & - & $9.5 \%$ & $6.3 \%$ & $75.7 \%$ \\
\hline Case 6 & $-10 \% P$ & -11.14 & 0.1380 & 0.6625 & $6.33 \times 10^{-4}$ & $-5.5 \%$ & $-12.5 \%$ & $-12.1 \%$ & $-97.7 \%$ \\
\hline Case 7 & $-10 \% w$ & - & 0.1477 & 0.7267 & $7.70 \times 10^{-3}$ & - & $-6.3 \%$ & $-3.6 \%$ & $-72.1 \%$ \\
\hline
\end{tabular}



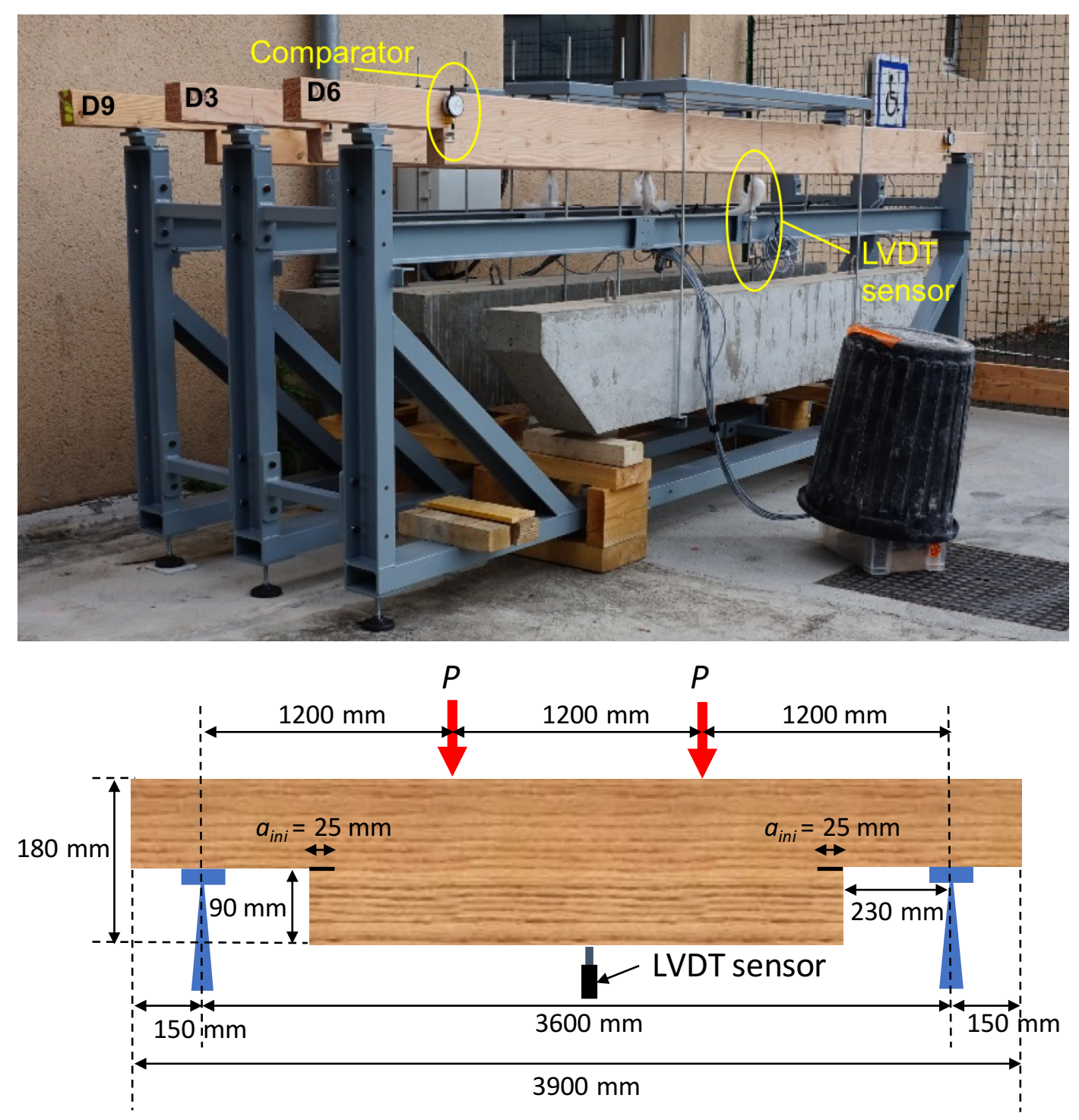

Figure 1: Notched Douglas fir and experimental setup description. 

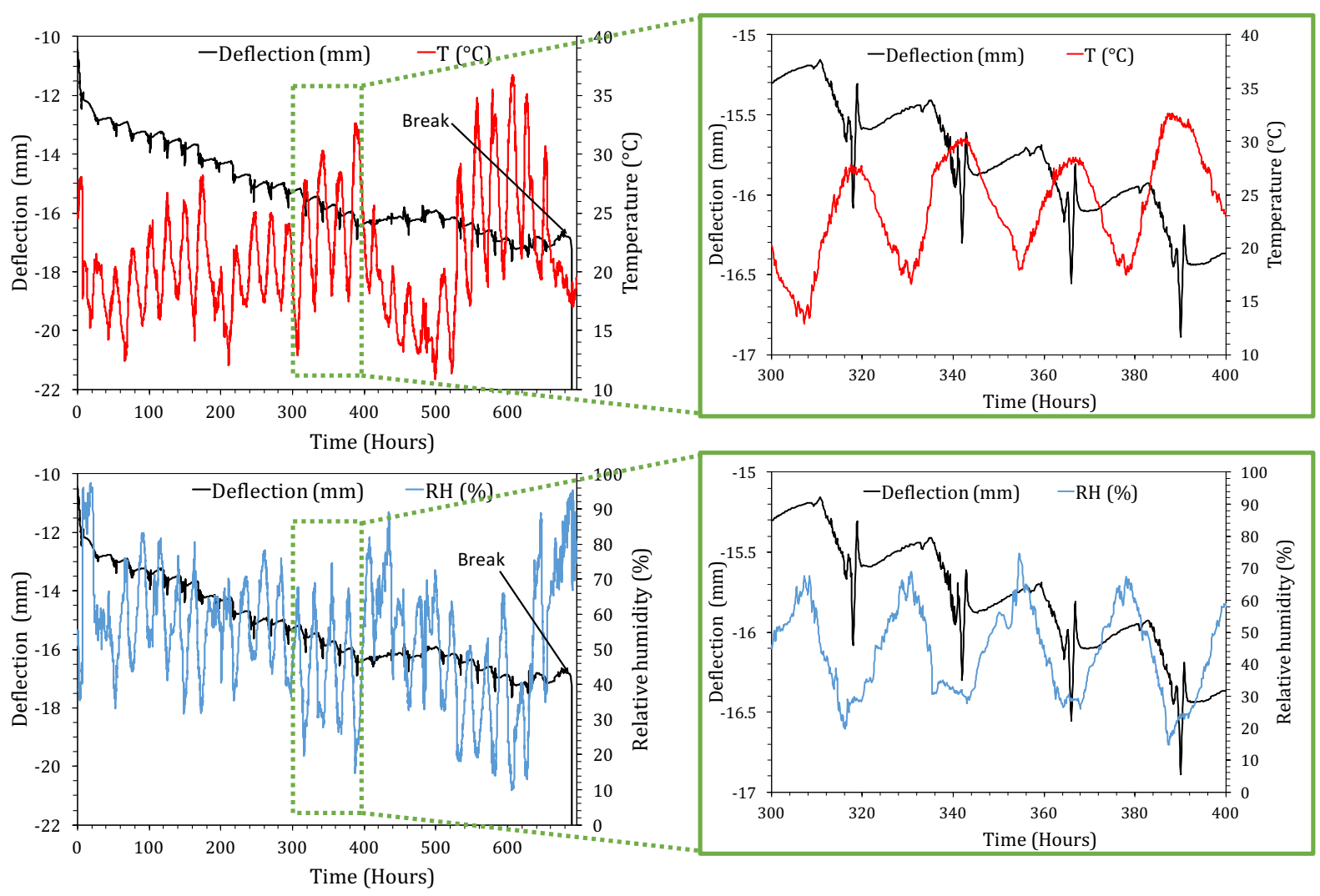

Figure 2: Recorded evolutions of deflection, temperature and relative humidity.

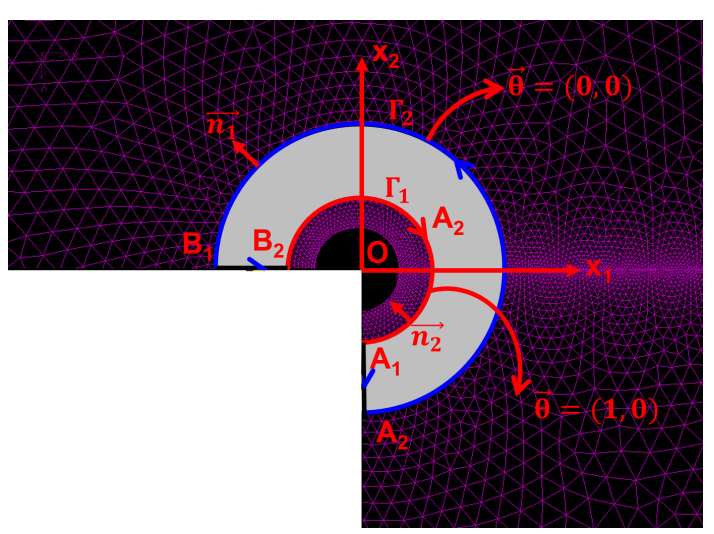

Figure 3: Integration domain $S$ on the notched beam and definition of the vector field $\vec{\theta}$. 


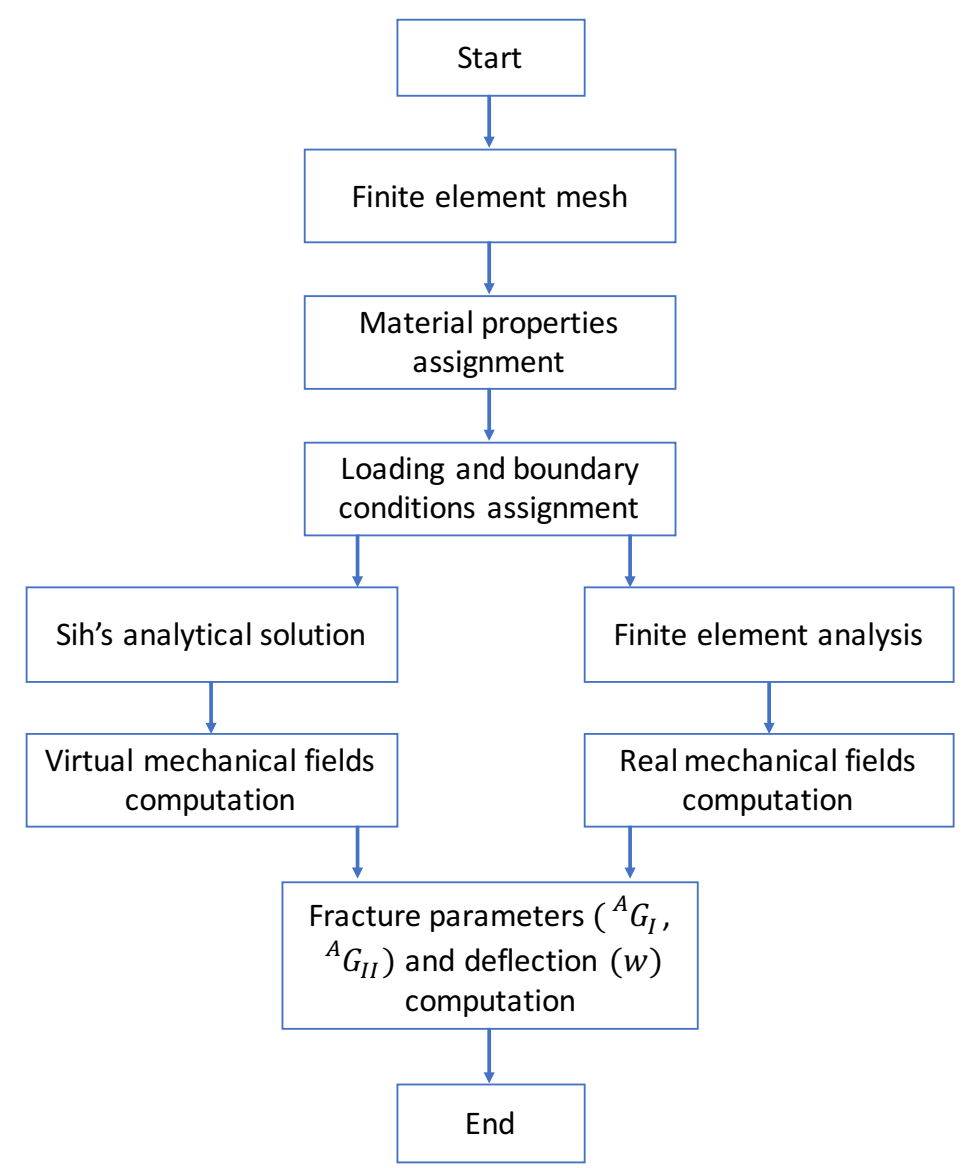

Figure 4. Flowchart for computing the fracture parameters 


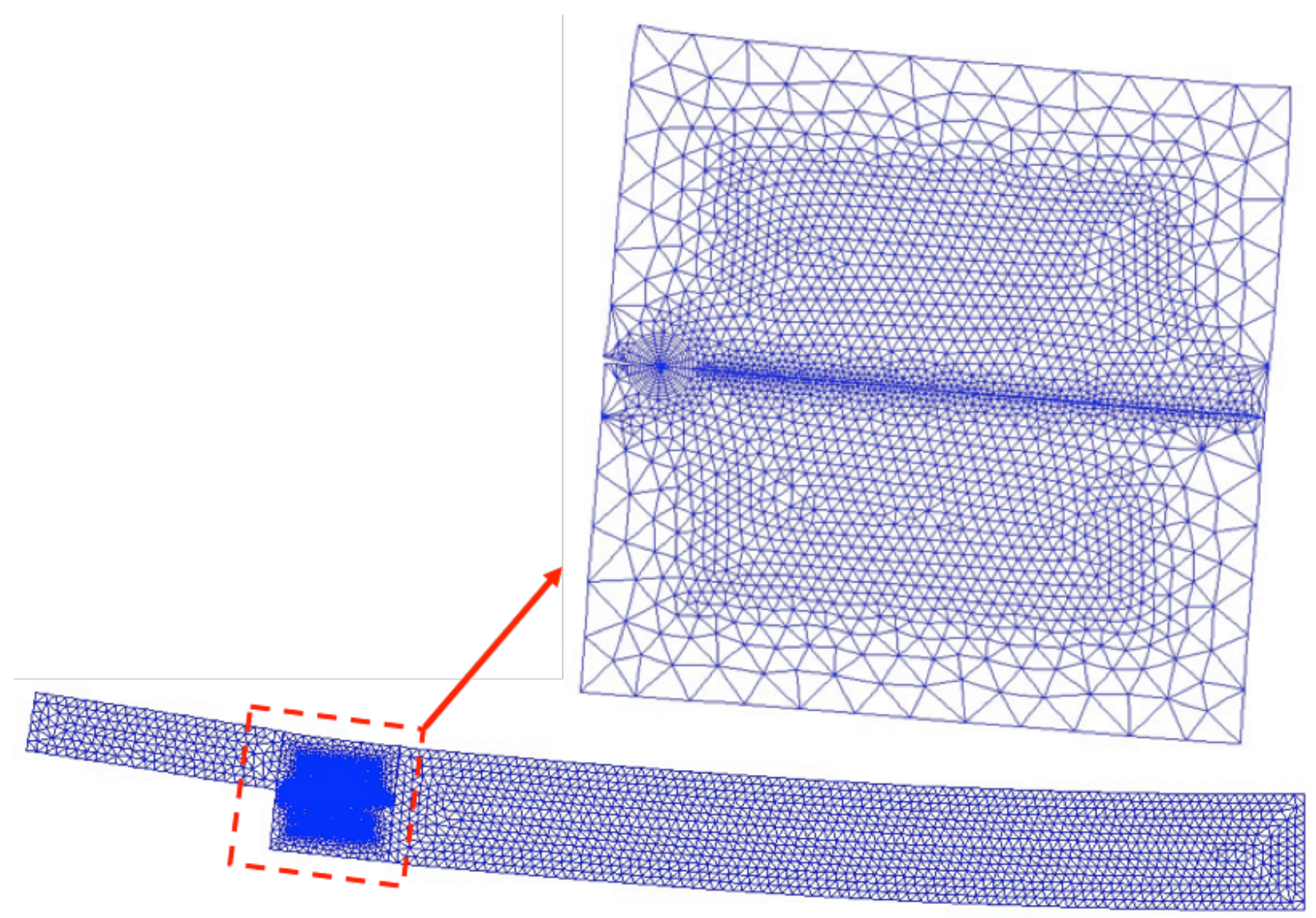

Figure 5: Mesh of a half beam modeled in Cast $3 \mathrm{~m}$.

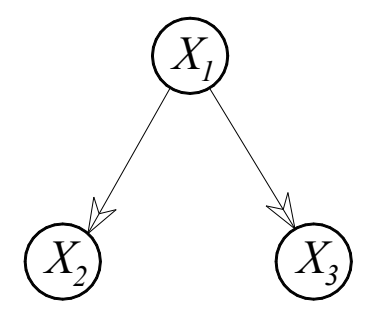

Figure 6: A Simple Bayesian Network. 


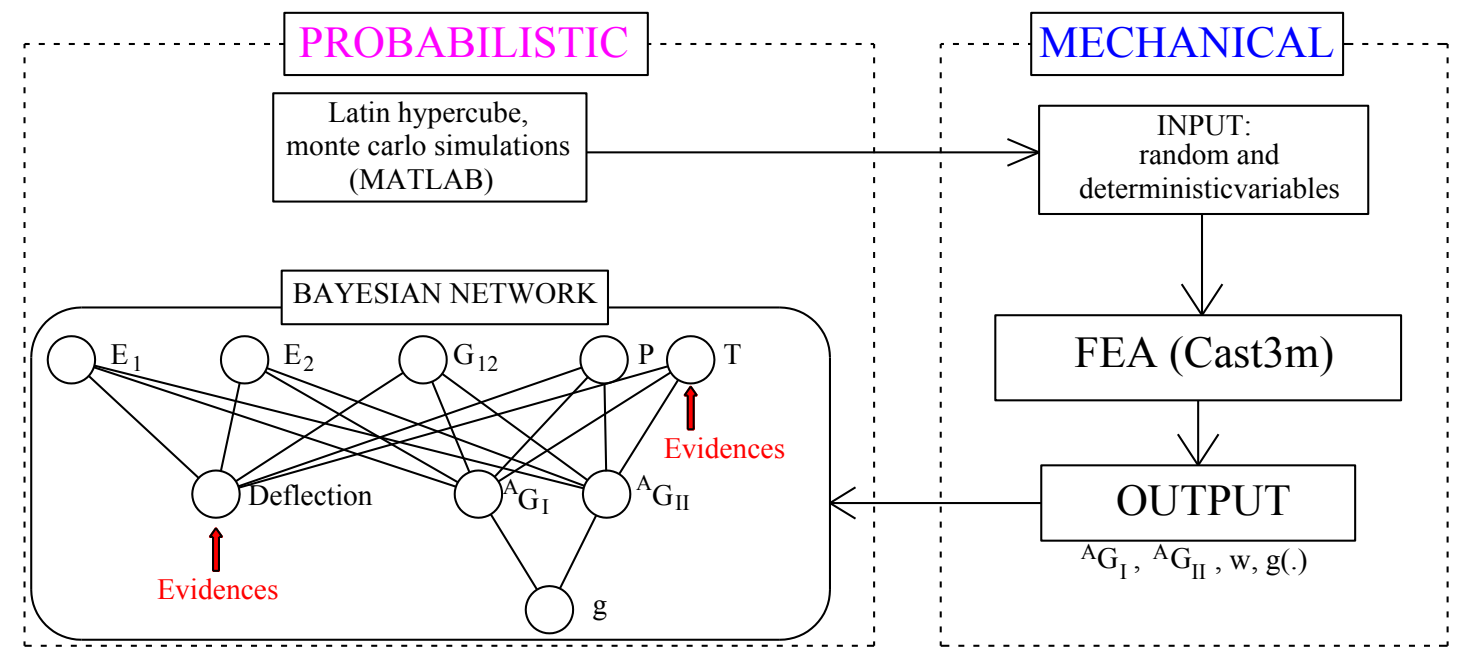

Figure 7: Combined mechanical and probabilistic methods used for reliability assessment and updating.
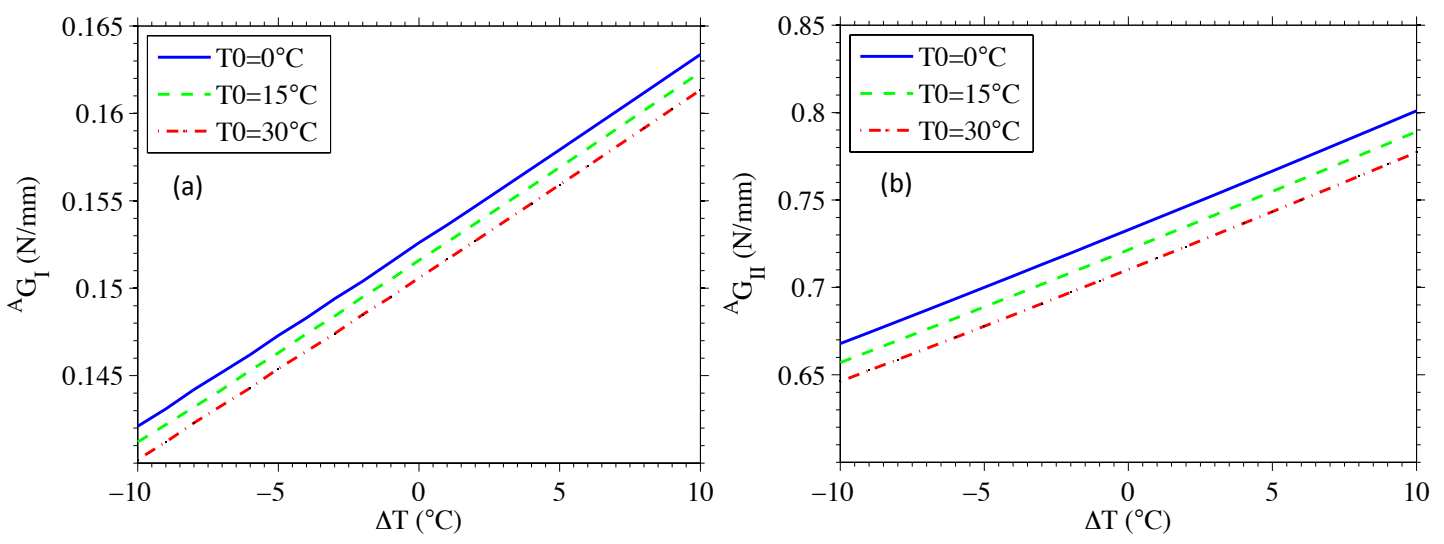

Figure $8:$ Influence of $\Delta T$ on the release energy rate in mode 1 and mode 2.
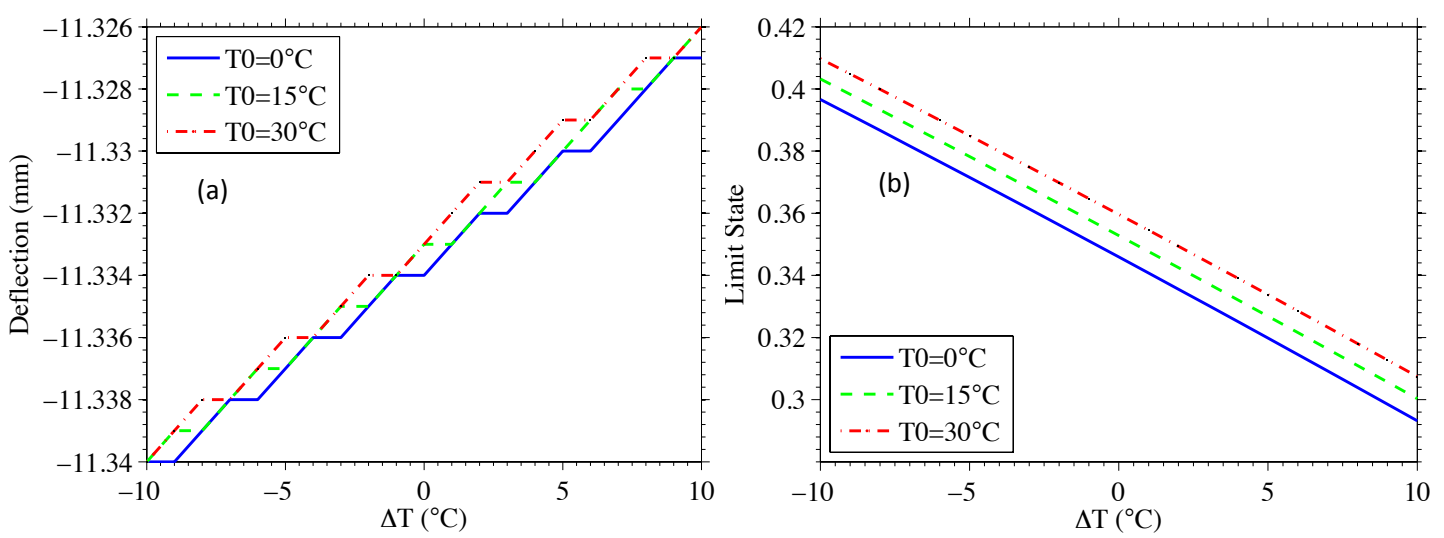

Figure $9:$ Influence of $\Delta T$ on the deflection and the limit state 

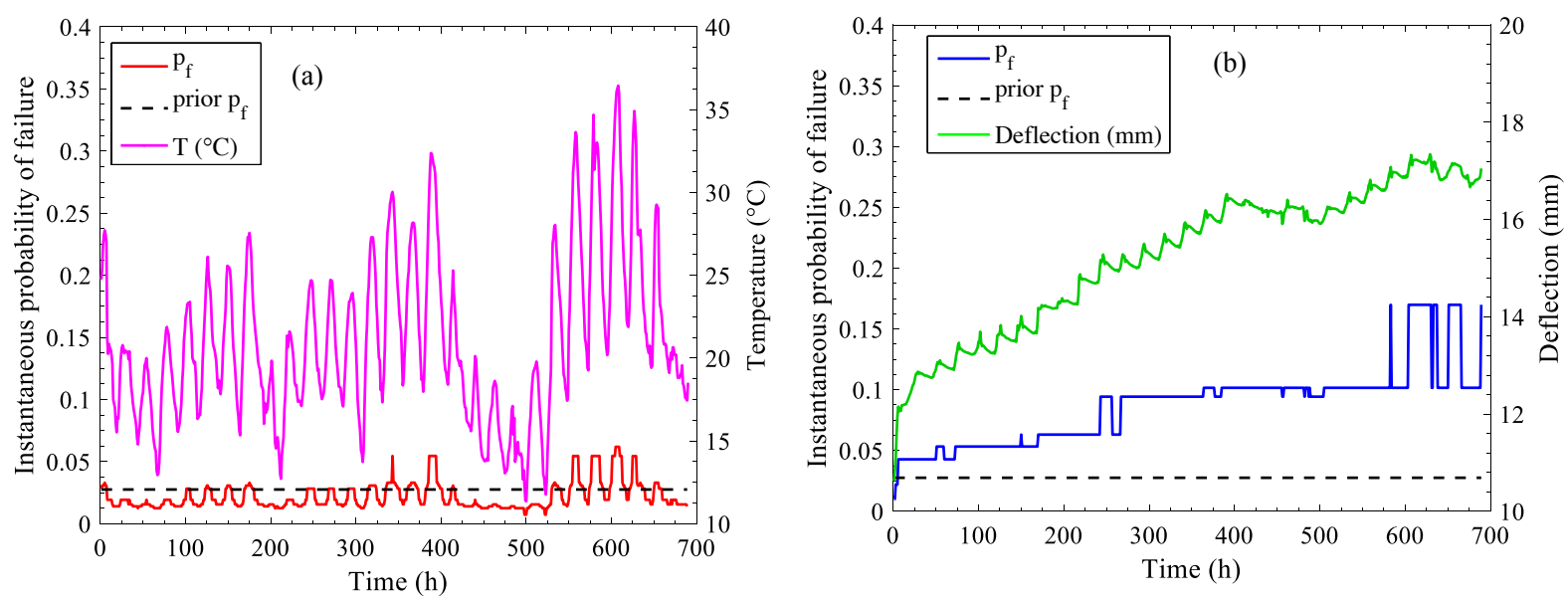

Figure 10: Updating of instantaneous probability of failure with evidences from: (a) Temperature variations only; (b) Deflection variations only.

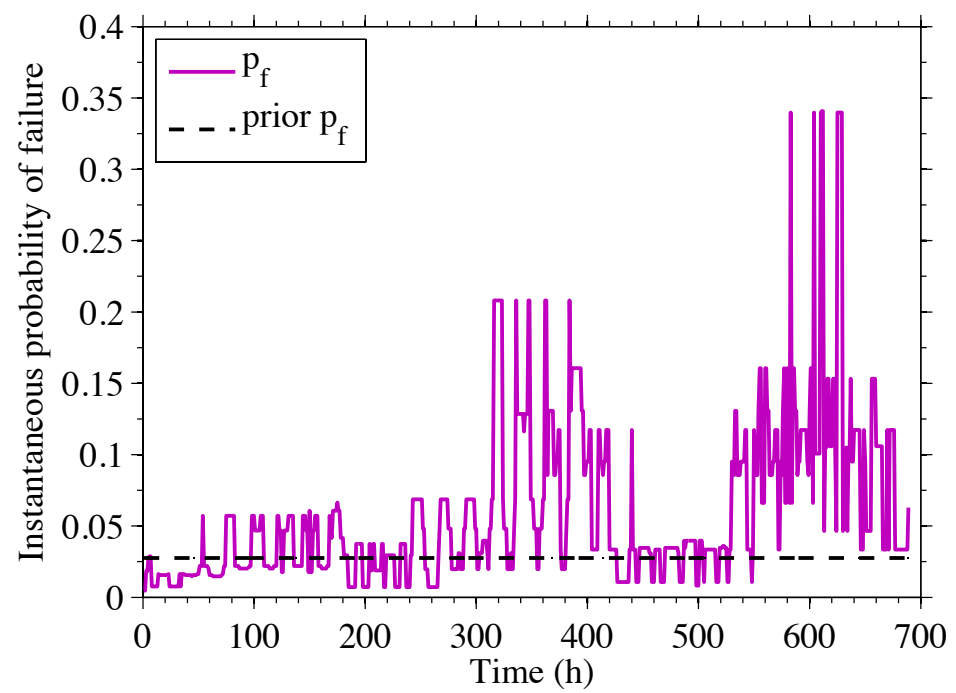

Figure 11: Updating of instantaneous probability of failure with evidences from temperature and deflection. 